\section{Drusen prevalence and pigmentary changes in Caucasians aged $18-54$ years}

G Silvestri'1,2, MA Williams², C McAuley' ${ }^{1}$, K Oakes', E Sillery' ${ }^{1}$, DC Henderson ${ }^{3}$, S Ferguson ${ }^{4}$, V Silvestri ${ }^{1}$ and KA Muldrew

as a function of age, such as the appearance of drusen, retinal pigment abnormalities, and patchy atrophy of the retinal pigment epithelium. These changes do not usually affect vision. ${ }^{1,2}$ Central vision can be severely affected if age-related macular degeneration (AMD) develops, characterised in its advanced form by geographic atrophy or choroidal neovascularisation. Drusen are the hallmark feature of ARM, and many studies have reported their prevalence ${ }^{1,3-14}$ and/or their natural history in US, ${ }^{15,16}$ European, ${ }^{17-19,20}$ Australian, ${ }^{11,21,22}$ and pooled cohorts. ${ }^{8}$ Although there is abundant information on drusen prevalence in those aged 50 years and older, only a minority of studies include subjects aged 50 years or less, either as part of cohorts for cross-sectional studies or at baseline in longitudinal studies. A minority of studies therefore can provide prevalence data on ARM in those under $50.3,6,7,12,14$ Data from the latest Beaver Dam report suggest that an even longer follow-up than their 15 years is necessary to quantify the risk of AMD associated with small hard drusen. ${ }^{16}$ An obvious means to achieve this is to enrol subjects at an earlier age than recruited to date in such longitudinal studies. A lower age limit of 40 years was set for enrolment into the Visual Impairment Project (VIP) ${ }^{7}$ the Los Angeles Latino Eye Study (LALES), ${ }^{12}$ the Baltimore Eye Survey, ${ }^{14}$ and the Barbados Eye Study Group. ${ }^{23}$ Forty-three years was the lower age limit for the Beaver Dam cohort $^{3}$ and 30 years for Chesapeake Bay watermen. ${ }^{24}$ The Colorado-Wisconsin study included subjects as young as 21 years, pooling data with the Beaver Dam cohort. We had noted that in young adults, that while the most common drusen diameter was $<63 \mu \mathrm{m}$, many drusen appeared to be substantially smaller than $63 \mu \mathrm{m}$. The aim of this study is to report the

\begin{abstract}
Age-related maculopathy (ARM) refers to characteristic changes that occur in the macula

Keywords: age-related maculopathy; drusen;

\section{Introduction}

${ }^{1}$ Centre for Vision \& Vascular Science, Queen's University of Belfast, Royal Victoria Hospital, Belfast, UK

${ }^{2}$ Ophthalmology, Belfast Health \& Social Care Trust, Belfast, UK

${ }^{3}$ Henderson's Optometry Practice, Ballyclare, UK

${ }^{4}$ Brogan's Optometry Practice, Lisburn, UK

${ }^{5}$ Central Angiographic Reading Facility, Centre for Vision \& Vascular Science, Queen's University, Belfast, UK

Correspondence: G Silvestri, Centre for Vision and Vascular Science, Queen's University of Belfast, Royal Victoria Hospital, Grosvenor Road, Belfast, Antrim BT12 6BA, UK

Tel: +44 (0)2890 632535;

Fax: +44 (0)2890 330744

E-mail: g.silvestri@qub.ac.uk

Received: 2 February 2012 Accepted in revised form: 1 June 2012

Published online: 17 August 2012

This work should be attributed to Centre for Vision \& Vascular Science, Queen's University of Belfast, UK and to Belfast Health \& Social Care Trust. Also, this work was presented as a poster at the ARVO Annual Conference 2005, FL, USA (Invest Ophthalmol Vis Sci 3298, 2005). 


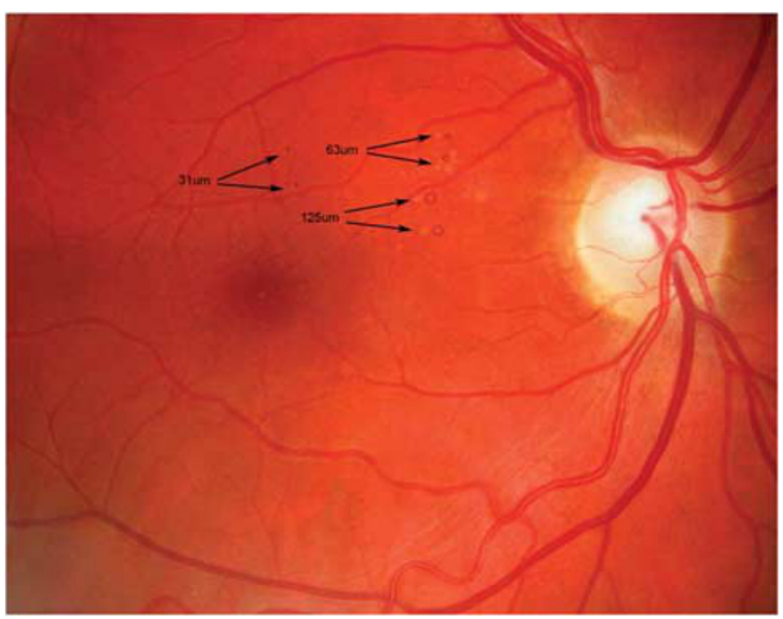

Figure 1 Example of drusen of different sizes, including drusen of $<31.5 \mu \mathrm{m}$ diameter.

frequency of drusen in subjects aged between 18 and 54 years, including a new smaller category of drusen size of $<31.5 \mu \mathrm{m}$ diameter (Figure 1).

\section{Materials and methods}

Digital retinal images from 500 consecutive subjects aged between 18 and 54 years attending two local optometry practices were included in the study. As this is an observational study to assess how frequently drusen occur in this age-group, power calculations were not required. A sample of 500 individuals and potentially 1000 eyes was selected as a reasonable number to study. The sample was opportunistic as subjects had attended the optometry practices on their own initiative. In both optometry practices retinal images are routinely taken of all subjects attending using a non-mydriatic $50^{\circ}$ Canon CR-DGi digital camera (Canon U.K Ltd, Reigate, UK). The images were downloaded in an anonymised and coded manner. The only information available to the operators was the subject's age. The images were randomised to allow each eye to be graded independently of the fellow-eye. Stereo images were not available.

A $6000 \mu \mathrm{m}$ AREDS retinal grid and circles of radius 500,1500 , and $3000 \mu \mathrm{m}$ for central, inner and outer subfields, respectively, were calibrated for the Canon CR-DGi camera using Adobe Photoshop, following the Wisconsin Age-Related Maculopathy grading system. ${ }^{25}$ Circles measuring 31.5, 63, 125 and $250 \mu$ m were calibrated to facilitate drusen sizing. Although the $31.5 \mu \mathrm{m}$ circle is not a feature of current grading systems it was found during preliminary grading of 200 eyes that many drusen fell well below the conventional smallest druse size of $63 \mu \mathrm{m}$. The investigators therefore created a new drusen category of $31.5 \mu \mathrm{m}$ to allow any future studies to capture progress from the $31.5 \mu \mathrm{m}$ to a larger size. The images and customised grading grid and circles were uploaded to the Central Angiographic Reading Facility (CARF) reading platform. Graders had undergone training at the CARF, Queen's University Belfast, UK. As quality control 100 images were graded by two graders and where a difference occurred, adjudication was by a third senior grader. Then all retinal images were graded by two graders using the Wisconsin Age-Related Maculopathy Grading System. Definitions of ARM and component lesions are as described by Klein et $a^{26}$. For drusen of the smaller size; that is, $<31.5 \mu \mathrm{m}$; when identification is potentially difficult, the definition of drusen used by Munch $e a^{27}$ was used: a drusen was defined as 'any bright element whose shape, colour or proximity to adjacent abnormality could not suggest that it was hard exudate'.

Statistical analysis was performed using SPSS (IBM Software and Systems, Armonk, NY, USA). Age (at the time of retinal imaging) was treated categorically in four groups: group one (16-24 years), group two (25-34 years), group three (35-44 years) and group four (45-54 years) for logistic regression analysis, and in the smaller age ranges of 7 years for descriptive statistics.

We certify that all applicable institutional and governmental regulations concerning the ethical use of human volunteers/animals were followed during this research.

\section{Results}

Of the 500 participants identified, images from 973 eyes in 488 individuals had been taken. The mean age of participants was 36.2 years (range 18-54). The quality of images was graded as good in $96.0 \%$, fair in $3.6 \%$, and poor in $0.4 \%$. Poor quality images were not graded and not all images were available for download, thus bilateral gradable images were available for 466 individuals and unilateral images for 19 individuals, making a total of 951 images. All three fields for grading were present in $98.9 \%$ of gradable images and two fields were present in $1.0 \%$. Of the 100 images graded by two graders to assess reliability, there was disagreement on twelve of the 100 eyes. Results of the senior grader were included in the analysis.

Drusen were identified within the grid in $91.5 \%$ of all gradable eyes and in 444 subjects. Bilateral drusen were present in $89.6 \%$ of individuals and $1.9 \%$ had unilateral drusen. Of the subjects with bilateral drusen, drusen sized $<31.5 \mu \mathrm{m}$ were present in $89.7 \%$ of eyes; drusen sized $>31.5 \mu \mathrm{m}$ and $<63 \mu \mathrm{m}$ were present in $45.9 \%$ of all eyes and drusen $>63 \mu \mathrm{m}$ and $<125 \mu \mathrm{m}$ were present in $1.7 \%$ of eyes (Table 1). No drusen greater or equal in size to $125 \mu \mathrm{m}$ was present in any eye. As the majority of 
Table 1 Presence of drusen and drusen size within the macular grid by size category

\begin{tabular}{|c|c|c|c|c|c|c|c|c|}
\hline \multirow[t]{2}{*}{ Number of drusen per eye } & \multicolumn{2}{|c|}{$\begin{array}{l}\text { Frequency of drusen } \\
\text { size }<31.5 \mu \mathrm{m}\end{array}$} & \multicolumn{2}{|c|}{$\begin{array}{l}\text { Frequency of drusen } \\
\text { size } 31.5<x<63 \mu \mathrm{m}\end{array}$} & \multicolumn{2}{|c|}{$\begin{array}{l}\text { Frequency of drusen } \\
\text { size } 63<\mathrm{x}<125 \mu \mathrm{m}\end{array}$} & \multicolumn{2}{|c|}{$\begin{array}{l}\text { Frequency of drusen } \\
\text { size } 125<\mathrm{x}<250 \mu \mathrm{m}\end{array}$} \\
\hline & Frequency & Percent & Frequency & Percent & Frequency & Percent & Frequency & Percent \\
\hline 0 & 98 & 10.31 & 515 & 54.15 & 935 & 98.32 & 951 & 100.00 \\
\hline$<10$ & 774 & 81.38 & 435 & 45.74 & 16 & 1.68 & 0 & 0.00 \\
\hline$<20$ & 74 & 7.78 & 1 & 0.11 & 0 & 0.00 & 0 & 0.00 \\
\hline$>20$ & 5 & 0.53 & 0 & 0.00 & 0 & 0.00 & 0 & 0.00 \\
\hline Total & 951 & 100.00 & 951 & 100.00 & 951 & 100.00 & 951 & 100.00 \\
\hline
\end{tabular}

Table 2 Drusen prevalence by size and age

\begin{tabular}{|c|c|c|c|c|c|c|c|c|c|}
\hline Age-group & $\begin{array}{c}\text { Number in group } \\
\text { with gradable } \\
\text { images }\end{array}$ & $\begin{array}{l}\text { Any drusen } \\
\text { present }\end{array}$ & $\begin{array}{c}\text { Percent } \\
\text { with any } \\
\text { drusen present }\end{array}$ & $\begin{array}{l}\text { Drusen size } \\
(<31.5 \mu \mathrm{m})\end{array}$ & Percent & $\begin{array}{c}\text { Drusen size } \\
(32<x<63 \mu m)\end{array}$ & Percent & $\begin{array}{c}\text { Drusen size } \\
(63<\mathrm{x}<125 \mu \mathrm{m})\end{array}$ & Percent \\
\hline $18-24$ & 142 & 132 & 92.96 & 130 & 91.55 & 48 & 36.36 & 3 & 2.11 \\
\hline $25-31$ & 172 & 155 & 90.12 & 152 & 88.37 & 71 & 45.81 & 0 & 0.00 \\
\hline $32-38$ & 212 & 192 & 90.57 & 183 & 86.32 & 103 & 53.65 & 6 & 2.83 \\
\hline $39-45$ & 245 & 229 & 93.47 & 226 & 92.24 & 142 & 62.01 & 4 & 1.63 \\
\hline $46-52$ & 165 & 148 & 89.70 & 146 & 88.48 & 67 & 45.27 & 3 & 1.82 \\
\hline $53-59$ & 15 & 12 & 80.00 & 12 & 80.00 & 7 & 58.33 & 0 & 0.00 \\
\hline
\end{tabular}

subjects $(85.9 \%)$ had symmetrical findings the remaining results will be given in terms of total eyes.

Logistic regression analysis was used to test association of age with drusen number and size, using four age groups as described in the 'Materials and methods'. The term 'drusen load' was used to take into account the number of drusen and drusen size per patient. Drusen load was significantly correlated with age $(P<0.001)$, increasing with age in age groups one to three. In group one $37.4 \%$ of eyes had drusen while $60.3 \%$ in group three had drusen. Group four however, although older, showed a reduction in percentage of eyes with drusen. A more detailed breakdown of drusen frequency by age and size in 6 year groupings is shown in Table 2.

Drusen were also analysed by the most severe drusen type (MSDT) present. The MSDT was defined by selecting the largest druse present and characterising its appearance and size according to the following categories: hard distinct drusen $<31.5 \mu \mathrm{m}$, hard indistinct drusen $<31.5 \mu \mathrm{m}$, hard distinct drusen $>31.5 \mu \mathrm{m}$ and $<63 \mu \mathrm{m}$, hard indistinct drusen $>31.5 \mu \mathrm{m}$ and $<63 \mu \mathrm{m}$, hard distinct drusen $>63 \mu \mathrm{m}$ and $<125 \mu \mathrm{m}$, soft distinct drusen $>63 \mu \mathrm{m}$ and $<125 \mu \mathrm{m}$, soft indistinct drusen $>63 \mu \mathrm{m}$ and $<125 \mu \mathrm{m}$. Of the 868 eyes with drusen present, the MSDT present was hard distinct drusen $<31.5 \mu \mathrm{m}$ in $419(48.3 \%)$, hard indistinct drusen $<31.5 \mu \mathrm{m}$ in $0.9 \%$, hard distinct drusen $>31.5 \mu \mathrm{m}$ and $<63 \mu \mathrm{m}$ in $47.2 \%$, hard indistinct drusen $>31.5 \mu \mathrm{m}$ and $<63 \mu \mathrm{m}$ in $1.5 \%$, hard distinct drusen $>63 \mu \mathrm{m}$ and $<125 \mu \mathrm{m}$ in $0.7 \%$, soft distinct drusen $>63 \mu \mathrm{m}$ and $<125 \mu \mathrm{m}$ in $1.0 \%$ and soft indistinct drusen $>63 \mu \mathrm{m}$ and $<125 \mu \mathrm{m}$ in $0.1 \%$. Drusen equal or greater than $125 \mu \mathrm{m}$ were not found in any eyes.

The most common locations for the most severe drusen were in the inner superior and outer superior subfields, followed by inner nasal. The central subfield was only the site of the MSDT in $6.7 \%$ of subjects. Drusen outside of the grid but in the posterior pole were present in $40.8 \%$ of eyes, with $60 \%$ of eyes having drusen $<31.5 \mu \mathrm{m}$ and $87.4 \%$ having drusen $>31.5 \mu \mathrm{m}$ and $<63 \mu \mathrm{m}$. Only $1 \%$ of eyes had drusen $>63 \mu \mathrm{m}$ and $<125 \mu \mathrm{m}$ in size. Nasal drusen were present in $12.9 \%$ of these eyes.

Very few eyes $(1.2 \%)$ showed pigmentary changes within the grid. Hyperpigmentation was present in $0.7 \%$ and hypopigmentation in the remaining $0.5 \%$. Pigmentary stippling was present in $1.5 \%$ of eyes.

\section{Discussion}

Very small drusen $(<31.5 \mu$ m diameter) were found in $89.7 \%$ of eyes. Drusen sized $>31.5 \mu \mathrm{m}$ and $<63 \mu \mathrm{m}$ were also common, evident in $45.9 \%$ of all eyes. However, drusen larger than $63 \mu \mathrm{m}$ were very uncommon, present in only $1.7 \%$ of eyes. No drusen of $125 \mu \mathrm{m}$ or larger was identified in this population.

Information on drusen prevalence in the age-group studied is not included in most studies on ARM, and the 'very small drusen' category has not been quantified previously in any age-group. 
The results are in good agreement with those few studies that include subjects $<50$ years of age. In the Beaver Dam population, drusen of any size were present in the macular area in $96.9 \%$ of those aged $43-54$ years. ${ }^{3}$ Among the Chesapeake Bay Watermen under 50 years of age, the prevalence of any drusen was $84 \% .{ }^{24}$ The prevalence of small drusen $<63 \mu$ m was $95.5 \%$ of 220 subjects aged between 20 and 46 years in a study of drusen heredity, ${ }^{27}$ but $40.5 \%$ of $40-49$ year olds in the Barbados Eye Study. ${ }^{23}$ The results of our study correlate well with those of the most comparable group for age, by Munch et al..$^{27}$ Our sample was $100 \%$ Caucasian and it is possible that lower prevalence in the Barbados Eye Study was due to ethnic factors.

In both Beaver Dam and the VIP the most common drusen size in younger age groups was drusen $<63 \mu \mathrm{m}$ diameter. It is not clear what proportion of these drusen $<63 \mu \mathrm{m}$ diameter would have fallen into the very small category of $31.5 \mu \mathrm{m}$.

The prevalence of larger soft drusen varies in different cohorts from $3.1 \%$ of 40 to 49 year olds in the VIP cohort, 7 to $7.1 \%$ of 43 to 54 year olds in the Beaver Dam cohort, ${ }^{3}$ and to $15.4 \%$ of the 40 to 49 year olds in the LALES cohort. ${ }^{12}$ This variation may partly be explained by variations in the definition of a soft druse. In our study soft drusen (soft distinct and soft indistinct) accounted for only $1.1 \%$ of drusen. In our sample there were no drusen $125 \mu \mathrm{m}$ or larger in size, while in the Eye Diseases Prevalence Group cohort the prevalence of drusen $125 \mu \mathrm{m}$ or larger was $1.4 \%$ in white females in the age-group 46-50 years. The results of our study were not unexpected as only $18.9 \%$ of our subjects were aged 46-54 years. $^{8}$

Drusen in the present study were distributed throughout most of the grid, with only $6.4 \%$ of drusen in the central field. It is possible that drusen become more prevalent centrally with increasing age and therefore central drusen are less common in this age-group. The most common location for drusen was in the inner and outer superior quadrants, which together accounted for $37.5 \%$ of all drusen found within the grid. Wang et al ${ }^{29}$ described the pattern of distribution of macular drusen and of early of ARM in the Beaver Dam Eye Study (BDES) cohort. In that study, drusen were also more frequent in the superior quadrant followed by the temporal, nasal, and inferior quadrants, in that order. Early ARM changes were more frequent in the superior and nasal quadrants followed by the temporal and inferior quadrants. In our study the location of the most severe druse followed a similar pattern as early ARM changes in the BDES, most frequently being in the superior quadrant $(37.5 \%)$, followed by the nasal quadrant (20.4\%). Extra-macular drusen were also common in this study, with $40.8 \%$ having drusen outside the grid, including $12.9 \%$ of subjects who had nasal drusen. The presence of nasal drusen could imply a familial trait, perhaps suggesting that a genetic predisposition to AMD is more likely in these individuals. $^{30}$

The strength of this study lies in the large sample size and the standardised grading used. However, there are two obvious drawbacks, limiting the applicability of findings. Firstly, the sample was representative only of the population of those attending an optometry practice, and secondly potentially confounding factors, particularly smoking, hypertension, family history and refractive error, were not recorded.

Drusen numbers and size increased significantly with increasing age, as would be anticipated. However, subjects in age-group four (45-54 years) demonstrated a decrease in number of drusen compared with the age category 36-44 years. This could have been due to the nature of the sample, which was opportunistically selected from subjects attending optometry practices. While some participants likely attended for advice on ophthalmic problems other than refractive issues, it is likely that those aged 18-44 had refractive errors. In contrast 45-54 year olds may have been attending for the first time with presbyopic symptoms and may have been emmetropic before this. This may explain the lower drusen prevalence in the older age-group, although the association between hyperopia and AMD is still under debate, with some cohort studies finding supportive evidence and others not. ${ }^{31-33}$ It is worth noting that a significant proportion of the general population is not emmetropic: in the Beaver Dam study, in the age-group 43-54 years, $22.1 \%$ of individuals were hyperopic and $43 \%$ were myopic. Our findings are not generalisable to the general population and should be considered frequency estimates rather than as prevalence data, but they are at least indicative of drusen prevalence in individuals with refractive errors, which account for over $60 \%$ of the population. ${ }^{34}$

Inaccuracies may have occurred in the grading of hard indistinct drusen, especially with only 50 degree images being available. Hard distinct drusen are easily identified, while drusen that are less definite were placed in the hard indistinct category. It is possible that the significance of these small indistinct drusen is questionable but as they represent a very small number in our series $2.4 \%$, it is unlikely that any misgrading would have a significant impact on overall drusen prevalence in this study. Stereo-photography and optical coherence tomography would be useful in future studies to assess the height of drusen.

The impetus for this study arose in relation to our group's work on risk assessment for AMD. Offspring of patients with AMD may ask about their risk of the 
condition, and whether preventative strategies are indicated at an early age. Genetic predisposition in AMD is now much better understood but clinically meaningful analyses of gene-gene and genetic-environment interactions are complex. The significance of very small drusen is not clear, and longitudinal studies would be required to determine their prognostic value. It is suggested that drusen associated with normal aging are distinct from those, which represented the earliest detectable signs of ARM. ${ }^{28}$ However , the presence of unexpected drusen, even if the drusen are very small, in individuals in this age-group could help identify those most at risk of ARM, justifying either targeted genetic testing to better assess risk and/or selective intervention with micronutrient supplementation and advice on modifiable lifestyle factors at a much earlier age.

\section{Summary}

\section{What was known before}

- Data on drusen prevalence in the under 50s is scarce.

- Many drusen in the under 50s are substantially $<63 \mu \mathrm{m}$ diameter.

\section{What this study adds}

- Very small drusen ( $<31.5 \mu \mathrm{m}$ diameter) are highly prevalent, being present in $89.7 \%$ of eyes in subjects aged $18-54$ years.

\section{Conflict of interest}

The authors declare no conflict of interest

\section{Acknowledgements}

We wish to acknowledge funding from R\&D HPSS NI RRG 4.41.

\section{References}

1 Augood CA, Vingerling JR, de Jong PT, Chakravarthy U, Seland J, Soubrane G et al. Prevalence of age-related maculopathy in older Europeans: the European Eye Study (EUREYE). Arch Ophthalmol 2006; 124: 529-535.

2 Hogg RE, Stevenson MR, Chakravarthy U, Beirne RO, Anderson RS. Early features of AMD. Ophthalmology 2007; 114: 1028.

3 Klein R, Klein BE, Linton KL. Prevalence of age-related maculopathy. The Beaver Dam Eye Study. Ophthalmology 1992; 99: 933-943.

4 Vingerling JR, Dielemans I, Hofman A, Grobbee DE, Hijmering M, Kramer CF et al. The prevalence of age-related maculopathy in the Rotterdam Study. Ophthalmology 1995; 102: 205-210.
5 Mitchell P, Smith W, Attebo K, Wang JJ. Prevalence of age-related maculopathy in Australia. The Blue Mountains Eye Study. Ophthalmology 1995; 102: 1450-1460.

6 Cruickshanks KJ, Hamman RF, Klein R, Nondahl DM, Shetterly SM. The prevalence of age-related maculopathy by geographic region and ethnicity. The Colorado-Wisconsin Study of Age-Related Maculopathy. Arch Ophthalmol 1997; 115: 242-250.

7 VanNewkirk MR, Nanjan MB, Wang JJ, Mitchell P, Taylor HR, McCarty CA. The prevalence of age-related maculopathy: the visual impairment project. Ophthalmology 2000; 107: 1593-1600.

8 Friedman DS, O'Colmain BJ, Munoz B, Tomany SC, McCarty C, de Jong PT et al. Prevalence of age-related macular degeneration in the United States. Arch Ophthalmol 2004; 122: 564-572.

9 Munoz B, Klein R, Rodriguez J, Snyder R, West SK. Prevalence of age-related macular degeneration in a population-based sample of Hispanic people in Arizona: Proyecto VER. Arch Ophthalmol 2005; 123: 1575-1580.

10 Gupta SK, Murthy GV, Morrison N, Price GM, Dherani M, John $\mathrm{N}$ et al. Prevalence of early and late age-related macular degeneration in a rural population in northern India: the INDEYE feasibility study. Invest Ophthalmol Vis Sci 2007; 48: 1007-1011.

11 Tikellis G, Robman LD, Dimitrov P, Nicolas C, McCarty CA, Guymer RH. Characteristics of progression of early agerelated macular degeneration: the cardiovascular health and age-related maculopathy study. Eye (Lond) 2007; 21: 169-176.

12 Varma R, Fraser-Bell S, Tan S, Klein R, Azen SP. Prevalence of age-related macular degeneration in Latinos: the Los Angeles Latino eye study. Ophthalmology 2004; 111: 1288-1297.

13 Dickinson AJ, Sparrow JM, Duke AM, Thompson JR, Gibson JM, Rosenthal AR. Prevalence of age-related maculopathy at two points in time in an elderly British population. Eye (Lond) 1997; 11, (Pt 3) 301-314.

14 Friedman DS, Katz J, Bressler NM, Rahmani B, Tielsch JM. Racial differences in the prevalence of age-related macular degeneration: the Baltimore Eye Survey. Ophthalmology 1999; 106: 1049-1055.

15 Bressler NM, Munoz B, Maguire MG, Vitale SE, Schein OD, Taylor HR et al. Five-year incidence and disappearance of drusen and retinal pigment epithelial abnormalities. Waterman study. Arch Ophthalmol 1995; 113: 301-308.

16 Klein R, Klein BE, Knudtson MD, Meuer SM, Swift M, Gangnon RE. Fifteen-year cumulative incidence of agerelated macular degeneration: the Beaver Dam Eye Study. Ophthalmology 2007; 114: 253-262.

17 Buch H, Nielsen NV, Vinding T, Jensen GB, Prause JU, la Cour M. 14-year incidence, progression, and visual morbidity of age-related maculopathy: the Copenhagen City Eye Study. Ophthalmology 2005; 112: 787-798.

18 Jonasson F, Arnarsson A, Peto T, Sasaki H, Sasaki K, Bird AC. 5-year incidence of age-related maculopathy in the Reykjavik Eye Study. Ophthalmology 2005; 112: 132-138.

19 Sparrow JM, Dickinson AJ, Duke AM, Thompson JR, Gibson JM, Rosenthal AR. Seven year follow-up of age-related maculopathy in an elderly British population. Eye (Lond) 1997; 11, (Pt 3) 315-324.

20 van Leeuwen R, Klaver CC, Vingerling JR, Hofman A, de Jong PT. The risk and natural course of age-related maculopathy: follow-up at $61 / 2$ years in the Rotterdam study. Arch Ophthalmol 2003; 121: 519-526. 
21 Wang JJ, Rochtchina E, Lee AJ, Chia EM, Smith W, Cumming RG et al. Ten-year incidence and progression of age-related maculopathy: the blue Mountains Eye Study. Ophthalmology 2007; 114: 92-98.

22 Mukesh BN, Dimitrov PN, Leikin S, Wang JJ, Mitchell P, McCarty CA et al. Five-year incidence of age-related maculopathy: the Visual Impairment Project. Ophthalmology 2004; 111: 1176-1182.

23 Schachat AP, Hyman L, Leske MC, Connell AM, Wu SY. Features of age-related macular degeneration in a black population. The Barbados Eye Study Group. Arch Ophthalmol 1995; 113: 728-735.

24 Bressler NM, Bressler SB, West SK, Fine SL, Taylor HR. The grading and prevalence of macular degeneration in Chesapeake Bay watermen. Arch Ophthalmol 1989; 107: 847-852.

25 Klein R, Davis MD, Magli YL, Segal P, Klein BE, Hubbard L. The Wisconsin age-related maculopathy grading system. Ophthalmology 1991; 98: 1128-1134.

26 Klein R, Klein BE, Jensen SC, Meuer SM. The five-year incidence and progression of age-related maculopathy: the Beaver Dam Eye Study. Ophthalmology 1997; 104: 7-21.

27 Munch IC, Sander B, Kessel L, Hougaard JL, Taarnhoj NC, Sorensen TI et al. Heredity of small hard drusen in twins aged 20-46 years. Invest Ophthalmol Vis Sci 2007; 48: 833-838.
28 Sarks SH, Arnold JJ, Killingsworth MC, Sarks JP. Early drusen formation in the normal and aging eye and their relation to age related maculopathy: a clinicopathological study. Br J Ophthalmol 1999; 83: 358-368.

29 Wang Q, Chappell RJ, Klein R, Eisner A, Klein BE, Jensen SC et al. Pattern of age-related maculopathy in the macular area. The Beaver Dam Eye Study. Invest Ophthalmol Vis Sci 1996; 37: 2234-2242.

30 Traboulsi EI. The challenges and surprises of studying the genetics of age-related macular degeneration. Am J Ophthalmol 2005; 139: 908-911.

31 Tao Y, Jonas JB. Refractive error and smoking habits in exudative age-related macular degeneration in a hospitalbased setting. Eye 2010; 24: 648-652.

32 AREDS Coordinating Center. T.E.C. Risk factors associated with age-related macular degeneration. A case-control study in the age-related eye disease study: Age-Related Eye Disease Study Report Number 3. Age-Related Eye Disease Study Research Group. Ophthalmology 2000; 107: 2224-2232.

33 Ikram MK, van Leeuwen R, Vingerling JR, Hofman A, de Jong PT. Relationship between refraction and prevalent as well as incident age-related maculopathy: the Rotterdam Study. Invest Ophthalmol Vis Sci 2003; 44: 3778-3782.

34 Wang Q, Klein KB, Moss R. SE. Refractive Status in Beaver Dam Eye Study. IOVS 1994; 35: 4344-4347. 